\title{
Como posso ajudar? Sentimentos e experiências do familiar cuidador de pacientes oncológicos
}

\author{
How can I help? Feelings and experiences of \\ the familiar caregiver of cancer patients
}

Tamara Figueiredo ${ }^{1,2}$, Andréia Pereira da Silva ${ }^{3}$, Rita Mânia Rosa Silva ${ }^{3}$, Juliana de Jesus Silva ${ }^{4}$, Carla Silvana de Oliveira e Silva ${ }^{5}$ Deivite Danilo Ferreira Alcântara ${ }^{6}$, Luís Paulo Souza e Souza ${ }^{4,7}$, Ana Augusta Maciel de Souza

${ }^{1}$ Gerência da Radioterapia, Hospital Dilson Godinho (HDG) - Montes Claros (MG), Brasil.

${ }^{2}$ Programa de Pós-graduação em Saúde do Adulto, Universidade Federal de Minas Gerais (UFMG) - Belo Horizonte (MG), Brasil.

${ }^{3}$ Departamento de Enfermagem, Faculdade de Saúde e Desenvolvimento Humano Santo Agostinho (FASA) - Montes Claros (MG), Brasil.

${ }^{4}$ Programa de Pós-graduação em Saúde Pública, UFMG - Belo Horizonte (MG), Brasil.

${ }^{5}$ Departamento de Enfermagem, Universidade Estadual de Montes Claros (UNIMONTES) - Montes Claros (MG), Brasil.

${ }^{6}$ Setor de Quimioterapia, Instituto Nacional de Câncer José Alencar Gomes da Silva (INCA) - Rio de Janeiro (RJ), Brasil.

${ }^{7}$ Departamento de Medicina, Universidade Federal de São João del-Rei (UFSJ) - São João del Rei (MG), Brasil.

DOI: http://dx.doi.org/10.7322/abcshs.v42i1.947

\section{RESUMO}

Introdução: O câncer é reconhecido como uma doença familiar, não apenas sob o ponto de vista genético, mas pelo impacto que gera. É uma doença que exige mudanças e reorganização na vida cotidiana, incorporando os familiares nos cuidados que o tratamento exige. Objetivo: Compreender os sentimentos de familiares cuidadores ao enfrentarem o diagnóstico, o tratamento e a evolução do câncer em um ente querido. Métodos: Pesquisa qualitativa, realizada com sete familiares cuidadores de parentes com câncer e em tratamento; no segundo semestre de 2011, em uma unidade de oncologia na cidade de Montes Claros, Minas Gerais. A coleta de dados foi realizada por meio de entrevistas, que foram gravadas, transcritas e analisadas pela técnica de análise do conteúdo. Resultados: Os familiares demonstraram sentimentos relacionados à mudança de vida, angústias e privações que o tratamento do câncer impõe. Declararam-se cansados, estressados, amedrontados e chorosos, vivendo uma grande oscilação emocional. Porém, na tentativa de superar o sofrimento, os mesmos se atem à religiosidade. Conclusão: O cuidado ao paciente oncológico não deve ser centrado apenas no doente ou na doença, mas na família que o rodeia, requerendo um cuidado humanizado, com apoio físico e psicossocial, proporcionando à família qualidade de vida durante o tratamento.

Palavras-chave: relações familiares; cuidadores; oncologia; apoio social.

\begin{abstract}
Introduction: The cancer is recognized as a family disease, not just under the genetic point of view, but also by the impact it generates. It is a disease that requires changes and reorganization in everyday life, incorporating the relatives in care that the treatment requires. Objective: To understand the feelings of family caregivers coping diagnosis, treatment and the development of cancer in a loved one. Methods: Qualitative research conducted with seven family members' caregivers of relatives with cancer and under treatment; in the second half of 2011, in an Oncology unit in the city of Montes Claros, Minas Gerais, Brazil. The data were collected through interviews, which were recorded, transcribed and analyzed by the content analysis technique. Results: The relatives have shown life-changingrelated feelings, troubles and privations that the cancer treatment requires. They declared himself tired, stressed, frightened and weeping, living a big emotional swing. However, in an attempt to overcome the suffering, they hold on to religion. Conclusion: The care of the oncological patient should not be only focused on the patient or the disease, but also in the family surrounding him, requiring a humanized care with physical and psychosocial support, providing the family quality of life during treatment.
\end{abstract}

Keywords: family relations; caregivers; medical oncology; social support.

Recebido em: 10/09/2016

Revisado em: 23/12/2016

Aprovado em: 18/01/2017

Autor para correspondência: Luís Paulo Souza e Souza - Campus Dom Bosco da Universidade Federal de São João del-Rei - Praça Dom Helvécio, 74 Dom Bosco - CEP: 36301-160 - São João del-Rei (MG), Brasil - E-mail: luis.pauloss@hotmail.com

Conflito de interesses: nada a declarar. 


\section{INTRODUÇÃO}

"Câncer" designa um grupo de mais de cem doenças diferentes, apresentando múltiplas causas e formas de tratamento. Apesar dos progressos da medicina nas últimas décadas em relação ao tratamento, o câncer ainda é visto como um agravo de alta letalidade ${ }^{1,2}$.

É uma doença que não causa impacto apenas no enfermo, mas também no universo familiar, exigindo mudanças e reorganização na vida cotidiana, de modo a incorporar os cuidados que o tratamento exige. As famílias enfrentam grandes dificuldades para lidar com essa doença, principalmente em seu grau avançado ${ }^{3}$. É comum que tanto familiares quanto doentes vivenciem os mesmos sentimentos de medo da cirurgia, medo da quimioterapia e seus efeitos colaterais, além da sensação de impotência diante da situação $0^{4,5}$.

Os sentimentos que perpassam uma família envolvida com o câncer envolvem uma relação de amor, sensibilidade, dor e sofrimento em conviver com o doente e seu tratamento. Tal condição e a forma de enfrentá-la afetam a maneira como os familiares desenvolvem o cuidado ${ }^{5-9}$.

As principais dificuldades experienciadas pelos cuidadores se relacionam à morte, demonstrando sentimentos de tristeza, insônia, estresse, depressão e, por vezes, doenças psicossomáticas como alergias e dores no corpo. Atreladas aos sentimentos, tem-se as diversas mudanças na vida diária, uma vez que o cuidado recai aos familiares do mesmo domicílio, não recebendo ajuda de outras pessoas. Contudo, autores enfatizam que são nesses momentos conflituosos que os cuidadores criam estratégias de apoio, citando a religiosidade, uma crença que transcende a natureza humana e conforta ${ }^{10,11}$.

Assim, reconhece-se que o câncer é uma doença familiar, não apenas sob o ponto de vista genético, mas pelo impacto que gera ${ }^{12}$. Portanto, conhecer os sentimentos vivenciados pelo familiar que cuida de pacientes com neoplasias torna-se importante para auxiliar a família a expressar seus desejos e ambições pessoais outrora privados, demonstrando e oferecendo estrutura sólida de suporte, cuidado e respeito ${ }^{11}$. A manifestação de uma doença aflora os sentimentos nas relações intrafamiliares, gerando dificuldade para adequação das modificações que ocorrem no cotidiano, daí a importância de se pesquisar sobre como ajudar no dimensionamento das modificações.

Este estudo objetivou compreender os sentimentos de cuidadores familiares ao enfrentarem o diagnóstico, o tratamento e a evolução do câncer em um ente querido.

\section{MÉTODOS}

Realizou-se um estudo descritivo, com abordagem qualitativa. A pesquisa foi realizada no segundo semestre de 2011, em uma unidade oncológica de um hospital na cidade de Montes Claros, norte de Minas Gerais, Brasil. Trata-se de uma instituição de referência no tratamento do câncer, desenvolvendo assistência especializada e integral na prevenção, detecção precoce, diagnóstico e tratamento.

O universo da pesquisa foi composto por familiares cuidadores de parentes com câncer em tratamento. Os critérios de inclusão estabelecidos para a participação da pesquisa foram: ter idade igual ou superior a 18 anos; ter parentesco com paciente oncológico; estar acompanhando o paciente na unidade oncológica escolhida no momento da pesquisa; ser capaz de se comunicar verbalmente; aceitar participar voluntariamente da pesquisa. Já o critério de exclusão foi: ser cuidador técnico do paciente sem apresentar parentesco.

A coleta de dados foi realizada por meio de entrevista aberta que continha a seguinte questão norteadora: "Como está sendo para você conviver com seu familiar com o diagnóstico de câncer?". As entrevistas foram gravadas individualmente, a fim de proporcionar liberdade de expressão ao sujeito entrevistado, ouvindo e compreendendo os sentimentos relatados. Posteriormente, foram transcritas, possibilitando o registro fidedigno de todas as informações. Visando manter o anonimato, os familiares foram identificados com pseudonomes, os quais foram escolhidos de maneira a levar ânimo e entusiasmo ao ambiente doloroso da oncologia. A coleta de dados se encerrou levando em conta a saturação dos dados ${ }^{13,14}$. Assim, foram entrevistados sete familiares.

Para análise dos dados, utilizou-se a técnica de análise do conteúdo, seguindo as etapas: organização das entrevistas para análise; leitura flutuante; seleção das unidades de análise (unidade de registro [frase] e unidade de contexto [parágrafo]); leitura exaustiva; recorte de trechos de fala; elaboração das categorias ${ }^{13}$.

Ressalta-se que os preceitos éticos foram seguidos. Os pesquisadores esclareceram os objetivos do estudo a todos os participantes, os quais, após concordarem, assinaram o Termo de Consentimento Livre e Esclarecido. A pesquisa foi aprovada pelo Comitê de Ética em Pesquisa da Universidade Estadual de Montes Claros, parecer número 3007/2011.

\section{RESULTADOS E DISCUSSÃO}

Os dados obtidos possibilitaram a análise de diferentes sentimentos e percepções dos familiares no dimensionamento e enfrentamento das modificações que ocorrem com a descoberta do câncer, que não raramente é associado à terminalidade. Emergiram das falas duas grandes categorias, "recebendo a notícia do câncer: vivências e mudanças na reorganização familiar" e; "esperando que o amanhã seja um novo dia", as quais serão discutidas a seguir.

\section{Recebendo a notícia do câncer: vivências e mudanças na reorganização familiar}

O diagnóstico do câncer representa para a família um impacto, pois ao serem constatados os primeiros sinais da doença, 
origina-se o sentimento de preocupação, principalmente quando é o primeiro caso na família, como notado nas falas a seguir:

É uma doença que nunca houve na família, pelo menos para a gente participar. (Esperança)

A preocupação maior da gente da família é durante a cirurgia, porque qualquer cirurgia não é um procedimento tão simples assim. Sentimos muita preocupação quando descobrimos, pois é sempre preocupante. (Fortaleza)

O câncer coloca os indivíduos e seus familiares em condição de fragilidade em virtude do próprio diagnóstico da doença, cujo estigma provoca, muitas vezes, dificuldades em lidar com a situação $0^{3,5}$. Os familiares demonstram preocupações com as consequências da doença tanto para o doente quanto para os demais membros da família. Com isso, surge a necessidade de informações, buscando alternativas para melhor tranquilizá-los. A fala a seguir evidencia isso:

Os meus irmãos ficaram preocupados, diziam: "Nossa! É câncer?" Só que os acalmei, dizendo que não era tão grave o caso do meu pai, tentei passar tranquilidade pra eles. (Altruísmo)

A reação das pessoas ao receberem a notícia do diagnóstico de uma doença como o câncer é de desespero, por não ser possível prever com exatidão o que irá acontecer ${ }^{4}$. Os familiares cuidadores vivenciam experiências diversas relacionadas à descoberta do câncer, que interfere diretamente na estruturação e organização familiar ${ }^{10}$.

Depois do diagnóstico, todo tipo de mudança que você pensar houve na minha vida e da nossa família, do marido dela, as filhas, os netos os irmãos (...) eu acho que mudou tudo. (Esperança)

São múltiplas as dificuldades encontradas por essas pessoas no âmbito do cuidar. É com muita garra e determinação que elas optam por serem cuidadoras, renunciando alguns sonhos e compromissos pessoais. Enfrentam mudanças na vivência e atividades familiares, tendo que se adaptarem a uma nova vida cheia de tensões e preocupações ${ }^{5,11}$. Porém, apesar do tempo disposto na dedicação aos cuidados ao familiar doente, os cuidadores se mostram dispostos, oferecendo o melhor cuidado possível.

A fala a seguir evidencia o abalo nas relações familiares após o surgimento da doença ${ }^{11}$ :

A minha família mudou. Agora percebo muita tristeza e dificuldades, e eu acho que mudou muita coisa na nossa convivência, nunca mais foi a mesma coisa, tá tudo mudado. Encontro muita dificuldade para cuidar dele, é eu sozinha, e isso já vai fazer um ano, e minha vida é só viajar, já tive em Belo Horizonte agora, e eu estou fora da minha casa. E para mim isso abalou muito a minha rotina, e até ficar longe da família da gente é uma grande dificuldade. (Ânimo)

Além do abalado na estrutura familiar, outra consequência direta relacionada ao cuidador foi a dificuldade para dormir, sendo esse um dos problemas mais enfrentados pelos familiares, pois eles permanecem em um constante estado de alerta, aguardando os pedidos de ajuda do enfermo ${ }^{15}$.

A gente muda assim, a nossa rotina, porque é muito cansativo, cansativo para quem tá acompanhando, para quem tá envolvido nessa situação. São noites sem dormir, dias conturbados, que por mais que não estamos por perto toda hora, a cabeça da gente fica ligada nessa situação, então a vida muda, muda radicalmente. (Alegria)

Devido à cronicidade e à gravidade do câncer, os familiares necessitam de assistência, exigindo reorganização para atender às necessidades cotidianas do enfermo ${ }^{3,5}$, como evidenciado pelas falas:

Sou a única da família que mora aqui na cidade, e os outros familiares não podem estar aqui o tempo todo, daí acabo abrindo mão de alguns afazeres (...). (Amor)

Sou dona de casa, tenho que lavar, passar, cozinhar e cuidar dos meus filhos, só que agora muda tudo, não tenho mais tempo para isso, preciso ficar no hospital com o meu esposo, ele precisa de mim. (Irmandade)

Ao observar a fala do entrevistado com pseudonome "Amor", notou-se o impacto maciço que o conviver com o câncer gera para a família, havendo exigências que provocam adaptações sempre desgastantes e difíceis para todos os envolvidos, em que sonhos, desejos e ambições são protelados para cuidar do paciente:

(...) fica um pouco complicado, pois tive que mudar minha rotina de vida, principalmente no trabalho, na faculdade, acabo faltando alguns dias (Amor).

Com a detecção do câncer, surgirão mudanças nas relações familiares, ou seja, uma relação de "compensação" na fala da entrevistada "Irmandade", no caso da mãe, o tempo para cuidar dos filhos é substituído pelas tarefas que a doença exige, uma vez que o esposo necessita do apoio da esposa: “[...] ele precisa de mim".

O câncer, por exigir cuidados específicos, seja para tratamento, seja para manutenção da saúde, faz com que a relação com o paciente e seus familiares cuidadores se torne bem próxima e contínua. Tal proximidade faz com que o familiar cuidador se sinta, muitas vezes, fraco e impotente, pelo fato de querer sempre fazer mais para ajudar e, às vezes, não poder. Sentimentos que podem ser evidenciados pelo depoimento: 
Às vezes a gente chora, às vezes a gente reza, está sempre sofrendo, não tem jeito, tem que ter muita paciência. E para nós que cuidamos o sofrimento não é tanto igual para quem tá com a doença, claro, mas é bem parecido. Cada dia dói mais um pouco, cada dia você não sabe o que fazer, mas é isso aí. O povo que era tranquilo, hoje só se vê lágrimas, eles não sorriem mais, é difícil ver um sorriso de adulto lá (na casa), só tristeza, e esse sofrimento vem prolongando há seis meses e não vem trazendo nada que presta. (Esperança)

As relações de cuidado que ocorrem em uma família envolvida com o câncer, embora estejam relacionadas com amor e sensibilidade, estão envolvidas com muita dor e sofrimento, afetando a maneira de desenvolver o cuidado prestado ao paciente. A cada momento, a família envolvida na tarefa do cuidado diário deixa transparecer o seu modo de agir e suas peculiaridades ${ }^{16}$.

Para mim está sendo muito difícil, porque a gente fica com a sensação que a pessoa vai morrer. Uma sensação bem assustadora. (Altruísmo)

O que sinto é uma grande ansiedade, uma mistura de nervosismo. Sinto medo, angústia, pois nunca sei o que irá acontecer amanhã. Cada dia é uma agonia, pois o meu tio está cada vez pior, tenho medo de receber a qualquer momento uma má notícia e temo que ele se acabe do meu lado. (Amor)

Estou cansada, estressada, pois há um balanço emocional muito grande na minha vida. Me sinto fraca, cansada, triste, a dor é muito grande. (Irmandade)

Dessa forma, os familiares que cuidam de pacientes em fase terminal enfrentam um trabalho pesado que os deixa emocionalmente esgotados, fisicamente exaustos e completamente subjugados ${ }^{10}$.

A família é permeada por uma diversidade de sentimentos envolvidos na relação de cuidado que podem ser observados nas entrevistas desta pesquisa, especialmente a impotência, que faz com que o cuidador fique deprimido e acredite que a situação tende a ficar mais difícil.

Difícil de lidar porque a gente se sente impotente demais diante de um inimigo tão forte. Agora minha irmã precisa da gente e a gente sente que fez tão pouco, a gente pergunta a Deus: $\mathrm{O}$ que eu posso fazer mais para ajudar? (Esperança)

Um sentimento de tristeza, porque é um tratamento doloroso, né!? Ver a pessoa sentir dor e você não pode fazer nada, às vezes a gente se sente impotente. Então resumindo: não é fácil! (Alegria)

Os familiares cuidadores, ao perceberem o familiar enfermo sentindo dor e deprimido, sentem-se impotentes, considerando-se como incapazes de acabar com o sofrimento do outro, gerando uma grande predisposição a doenças psicológicas como resultado dos estressores nessa relação ${ }^{15}$.

\section{Esperando que o amanhã seja um novo dia}

Durante o desenvolvimento da doença, a família constrói o seu alicerce de apoio para se abastecer de forças para enfrentar a doença. Atem-se, principalmente, à espiritualidade e, independentemente da religião, relataram que acreditam em Deus. A religiosidade representa uma influência na vida dessas pessoas, pois desenvolvem fé, reforçando o bem-estar emocional, como notado na fala a seguir:

A gente acha que fez pouco e procura força para fazer mais, então ao mesmo tempo, é uma coisa que a gente sabe que é normal, num é? Às vezes a gente chora, às vezes a gente reza, está sempre sofrendo, não tem jeito, tem que ter muita paciência. E ela, a minha irmã sempre foi a rocha, assim quando a gente fica preocupado, ela tem uma palavra amiga, companheira. (Esperança)

O apoio recebido, seja de pessoas fora do círculo familiar ou dos próprios parentes, faz com que a família suporte melhor as adversidades geradas pelo câncer. Autores reforçam que uma família que apresenta base estrutural sólida tem mais facilidade em desenvolver ações de união, carinho, cuidado e amor, os quais, devido à doença, ficam pouco demonstrados ${ }^{11}$.

Os cuidadores procuram diversas maneiras de diminuir seu sofrimento. A busca pela força na religiosidade faz com que o cuidador familiar vivencie a proteção de um "ser maior", que o ajuda a superar as dificuldades ${ }^{7}$. As falas a seguir evidenciam essas discussões:

Sou uma pessoa que fica insegura, mas só confio mesmo é em Deus. Busco paz na igreja, assim, para mim é tudo, os irmãos oram, fazem orações. Estamos buscando confiança em Deus. (Ânimo)

A gente confia muito, busca muito conforto em Deus, porque isso é uma força fundamental. Aqui no hospital existem os médicos que estão conduzindo, mas à frente deles está Deus. É muito triste e dolorido acompanhar, e no caso que é o meu pai, eu só fico mais tranquila pois ele mesmo me passa essa tranquilidade. Por ele eu fico, mas no geral, isso me incomoda muito. (Altruísmo)

Mas busco forças dos céus, em Deus, na família, temos muita fé. (Amor)

Estudiosos $^{17}$ afirmam que, entre os pontos fortes de apoio, a espiritualidade demonstra ser uma estratégia de fortalecimento e direcionamento da vida familiar.

Minha sorte é Deus, a nossa religiosidade, pois buscamos consolo dos céus, os nossos amigos e parentes também nos ajudam muito, dão consolo. (Irmandade)

Apesar de o homem viver numa época cientificista, observa-se que os indivíduos, em algum momento de suas vidas, externalizam suas crenças relacionadas à espiritualidade, principalmente em situações de acometimento pelo câncer. Assim, a espiritualidade se 
apresenta como ferramenta utilizada para o enfrentamento de crises, proporcionando resiliência ${ }^{8,18}$.

Referenciadas como práticas já vivenciadas e que são intensificadas com o diagnóstico do câncer, a espiritualidade e a religiosidade são demonstradas pelos familiares como instrumentos de força e resistência. Para eles, a superação de cada etapa da doença é conferida à fé em uma energia maior que é um "Deus", o qual demonstra e aplica o seu poder de curar ${ }^{19}$.

Enquanto houver esperança, as famílias irão à luta. Mesmo que em alguns momentos a família manifeste o dilema da incerteza de que tudo parece chegar ao fim, estarão sempre à espera de uma perspectiva positiva:

Mas a gente sempre espera que amanhã seja outro dia, que ela vai amanhecer boa, que ela vai para casa. (Esperança)

Notou-se que as palavras do familiar refletem sentimentos díades (força versus temor; anseio versus coragem), elucidando vivências positivas mesmo diante de todas as adversidades.

Com o desenvolvimento do tratamento, ressurge a possibilidade de manutenção da vida e do retorno ao cotidiano. Os familiares acreditam que podem alcançar a cura por meio do tratamento, adotando outro significado para a trajetória, e colocam a morte o mais distante possível ${ }^{2,3,20}$.

É satisfatório notar que, mesmo estando cientes da doença, os familiares esperam e acreditam sempre na possibilidade de cura. Percebem que encarar com coragem a doença é fator benéfico, trazendo respostas positivas a todos os membros da família. Autores destacam, ainda, que o câncer se apresenta intimamente associado à finitude da vida, e os familiares envolvidos acabam por iniciar uma nova etapa de sua existência, vivenciando com fé e grande intensidade todos os momentos, como se fossem os últimos, encarando a existência humana de forma mais saudável e verdadeira ${ }^{21}$.

Foi possível observar que o câncer marca a vida da família. O contato com as experiências dos familiares possibilitou a compreensão dos sentimentos, das angústias, das privações e das esperanças vivenciados durante o tratamento do câncer. Os cuidadores se declararam cansados, estressados, amedrontados, tristes, ansiosos, nervosos e, muitas vezes, chorosos, vivendo uma grande oscilação emocional.

Observou-se, ainda, que os cuidadores sofrem com o sentimento de impotência diante da situação. Destacou-se a angústia como ponto forte do sofrimento, ao presenciarem os sintomas da doença.

Por outro lado, visando amenizar o sofrimento e a alimentar as esperanças, os entrevistados recorriam à fé e às práticas religiosas para se fortalecerem e superarem os momentos de dificuldade. Percebeuse que a espiritualidade e a religiosidade apresentaram influência marcante na vida dessas pessoas, renovando o acreditar que dias melhores virão. Os pesquisados citaram um "Deus" como provedor de tudo e entregavam suas vidas e de seus familiares à Ele.

Nesse sentido, destaca-se que é preciso desenvolver uma atenção especial aos familiares, pois deixam de lado seus compromissos domésticos, trabalhos, estudos e laços com outros membros da família para se dedicarem integralmente ao processo do tratamento. O cuidado ao paciente oncológico não deve ser centrado apenas no doente ou na doença, mas em toda a família que o rodeia. Os profissionais que lidam com tal situação devem compreender os problemas enfrentados por eles e elaborar intervenções que reforcem o apoio físico e psicossocial, proporcionando à família qualidade de vida durante o tratamento.

\section{REFERÊNCIAS}

1. Borges ADVS, Silva EF, Toniollo PB, Mazer SM, Valle ERM, Santos MA. Percepção da morte pelo paciente oncológico ao longo do desenvolvimento. Psicol Estud. 2006;11(2):361-9. http://dx.doi.org/10.1590/S1413-73722006000200015

2. Sales CA, Matos PCB, Mendonça DPR, Marcon SS. Cuidar de um familiar com câncer: o impacto no cotidiano de vida do cuidador. Rev Eletr Enf. 2010;12(4):616-21.

3. Carvalho CSU. A necessária atenção à família do paciente oncológico. Rev Bras Cancerol. 2008;54(1):87-96.

4. Souza MGG, Santos FHE. O olhar que olha o outro... um estudo com familiares de pessoas em quimioterapia antineoplásica. Rev Bras Cancerol. 2008;54(1):31-41.

5. Salci MA, Marcon SS. A convivência com o fantasma do câncer. Rev Gaúcha Enferm. 2012;31(1):18-25.

6. Menezes CNB, Passareli PM, Drude FS, Santos MA. Câncer infantil: organização familiar e doença. Rev Mal-Estar Subjet. 2007;7(1):191-210.
7. Aquino VV, Zago MMF. The meaning of religious beliefs for a group of cancer patients during rehabilitation. Rev Latino-Am Enferm. 2007:15(1):42-7. http://dx.doi.org/10.1590/S0104-11692007000100007

8. Menossi MJ, Zorzo JCC, Lima RAG. A dialógica vida/morte no cuidado do adolescente com câncer. Rev Latino-Am Enferm. 2012;20(1):126-34.

http://dx.doi.org/10.1590/S0104-11692012000100017

9. Silva CAM, Acker JIBV. O cuidado paliativo domiciliar sob a ótica de familiares responsáveis pela pessoa portadora de neoplasia Rev Bras Enferm. 2007;60(2):1504. http://dx.doi.org/10.1590/S0034-71672007000200005

10. Volpato FS, Santos GRS. Pacientes oncológicos: um olhar sobre as dificuldades vivenciadas pelos familiares cuidadores. Imaginário. 2007;13(14):511-44 http://dx.doi.org/10.11606/issn.1981-1616.v13i14p511-544

11. Hayashi VD, Chico E, Ferreira NMLA. Enfermagem de família: um enfoque em oncologia. Rev Enferm UERJ. 2006;14(1):13-20. 
12. Barreto TS, Amorim RC. A família frente ao adoecer e ao tratamento de um familiar com câncer. Rev Enferm UERJ. 2010;18(3):462-7.

13. Bardin L. Análise de conteúdo. Lisboa: Edições 70; 2009.

14. Venâncio JL. Importância da atuação do psicólogo no tratamento de mulheres com câncer de mama. Rev Bras Cancerol. 2004;50(1):55-63.

15. Pereira LL, Dias ACG. O familiar cuidador do paciente terminal: o processo de despedida no contexto hospitalar. Psicol. $2007 ; 38(1): 55-65$

16. Inocenti A, Rodrigues IG, Miasso Al. Vivências e sentimentos do cuidador familiar do paciente oncológico em cuidados paliativos. Rev Eletr Enferm. 2009;11(4):858-65.

17. Sanchez KOL, Ferreira NMLA, Dupas G, Costa DB. Apoio social à família do paciente com câncer: identificando caminhos e direções. Rev Bras Enferm. 2010;63(2):290-9. http://dx.doi.org/10.1590/S0034-71672010000200019

18. Silva DIS. Significados e práticas da espiritualidade no contexto dos cuidados paliativos em pacientes oncológicos adultos. Rev HCPA. 2011;31(3):353-8.

19. Ferreira NML, Dupas G, Costa DB, Sanchez KOL. Câncer e família: compreendendo os significados simbólicos. Ciên Cuid Saúde. 2010;9(2):269-77.

http://dx.doi.org/10.4025/cienccuidsaude.v9i2.8749

20. Selli L. Dor e sofrimento na tessitura da vida. O Mundo da Saúde. 2007;31(2):297-300.

21. Visoná F, Prevedello M, Souza EM. Câncer na família: percepções de familiares. Rev Enferm UFSM. 2012;2(1):145-55. http://dx.doi.org/10.5902/217976923943 